\title{
Neurofibromatosis type I
}

Neurofibromatose tipo I

Flávia Souza Moraes', Weika Eulálio de Moura Santos², Gustavo Henrique Salomão³

\begin{abstract}
The neurofibromatosis type 1 is a autosomal dominant disease which the diagnosis is made based on clinical criteria. Its three main features - neurofibromas, cafe au lait macules and Lisch nodules occur in up to $90 \%$ of the pacients until puberty. We documented a clinical case of a young male pacient who had the diagnosis of neurofibromatosis type 1 and family history, describing its clinical aspects and radiological features.
\end{abstract}

Keywords: Neurofibromatosis type 1; Glioma; Magnetic resonance imaging; Case reports

\section{RESUMO}

A neurofibromatose tipo I é uma doença autossômica dominante cujo diagnóstico presuntivo é feito com base em critérios clínicos. As três principais manifestações: neurofibromas, manchas café com leite e nódulos de Lisch ocorrem em mais de $90 \%$ dos pacientes até a puberdade. Relatamos o caso de um paciente jovem com diagnóstico de neurofibromatose tipo I e história familiar positiva para a doença, comentando seus aspectos clínicos e achados nos exames de imagem.

Descritores: Neurofibromatose tipo I; Glioma; Imagem por ressonância magnética; Relatos de casos

\footnotetext{
${ }^{1} 1^{\text {st }}$ year resident physician at the Ophthalmology Department, ABC Medical School (FMABC), Santo André/SP, Brazil.

2 Physician at the Paediatric Ophthalmology and Strabismus Departments, ABC Medical School (FMABC), Santo André/SP, Brazil.

${ }^{3}$ Chief physician at the Paediatric Ophthalmology Department, ABC Medical School (FMABC), Santo André/SP, Brazil.
}

Work conducted at the Ophthalmology Service of ABC Medical School (FMABC), Santo André/SP, Brazil.

The authors declare no conflicts of interest

Received for publication: 10/8/2010 - Accepted for publication: 5/12/2012 


\section{INTRODUCTION}

$\mathbf{N}$ eurofibromatosis type 1 (NF1), also called peripheral neurofibromatosis or von Recklinghausen disease, is an autosomal dominant (AD) disease with a highly variable clinical presentation. ${ }^{(1.2)}$ Its incidence ranges from 1/ 2000 to $1 / 7800$ live births, making it one of the most frequent autosomal dominant genetic diseases. It has been observed in different parts of the world, in all races and in both sexes. ${ }^{(1)}$

Half of the cases are caused by new mutations. The mutation rate for the NF1 gene is $1 / 10,000$; this is due to the large size and unusual internal structure of the gene, which predispose it to deletions and mutations. ${ }^{(1)}$

A correlation has not been established between the mutated region of the NF1 gene and the phenotype of patients with the syndrome. Variable expression is one of the most striking features of NF1. ${ }^{(1)}$

Presumptive diagnosis of NF1 is based on clinical criteria. Its three main features - neurofibromas, café-au-lait spots and Lisch nodules - occur in over $90 \%$ of patients until puberty. ${ }^{(1-3)}$

Currently there is no cure for NF1, but mitigation measures can improve the prospects of life of affected individuals. These patients generally have a normal life expectancy, lead productive academic and professional careers and have a regular affective life. Genetic counselling is important to guide the parents of affected children and to inform them about the risk of recurrence in other pregnancies. ${ }^{(1)}$

\section{Case report}

Male, 16-year-old patient born and raised in Santo André/ SP, Brazil, referred to the paediatric ophthalmology service of the $\mathrm{ABC}$ Medical School under investigation for neurofibromatosis type 1 . The patient had no ocular symptoms and no history of ophthalmic disease, obstetric complications or neuropsychomotor development deficits. Family history revealed a maternal grandmother and mother with neurofibromatosis. The patient's mother died of lung cancer, and his sister was under investigation for NF1.

On general examination, café-au-lait spots were seen on the trunk and abdomen. (Figure 1)

Ophthalmic examination showed a corrected visual acuity of 20/30 in both eyes. The patient used corrective lenses of $+0.25 \mathrm{SD},-0.75 \mathrm{CD}, 5^{\circ}$ in the RE and $0 \mathrm{SD},-0.75 \mathrm{CD}, 165^{\circ}$ in the LE. Symmetrical pupils, normal pupillary light reflexes, no relative afferent pupillary defect, extrinsic muscles without alterations. Biomicroscopy showed Lisch nodules in both eyes, without other changes. Fundus examination showed a fully attached retina, an optic disc with sharp edges and mild temporal pallor, a physiologic cup and a normal macula in both eyes.

Perimetry showed a loss of sensitivity in the temporal hemifields compatible with the suprachiasmatic lesion observed on an MRI brain scan, without signs of deterioration when compared to the first studies.

Optical coherence tomography (OCT) showed no changes. A head and brain MRI showed a mass involving the optic
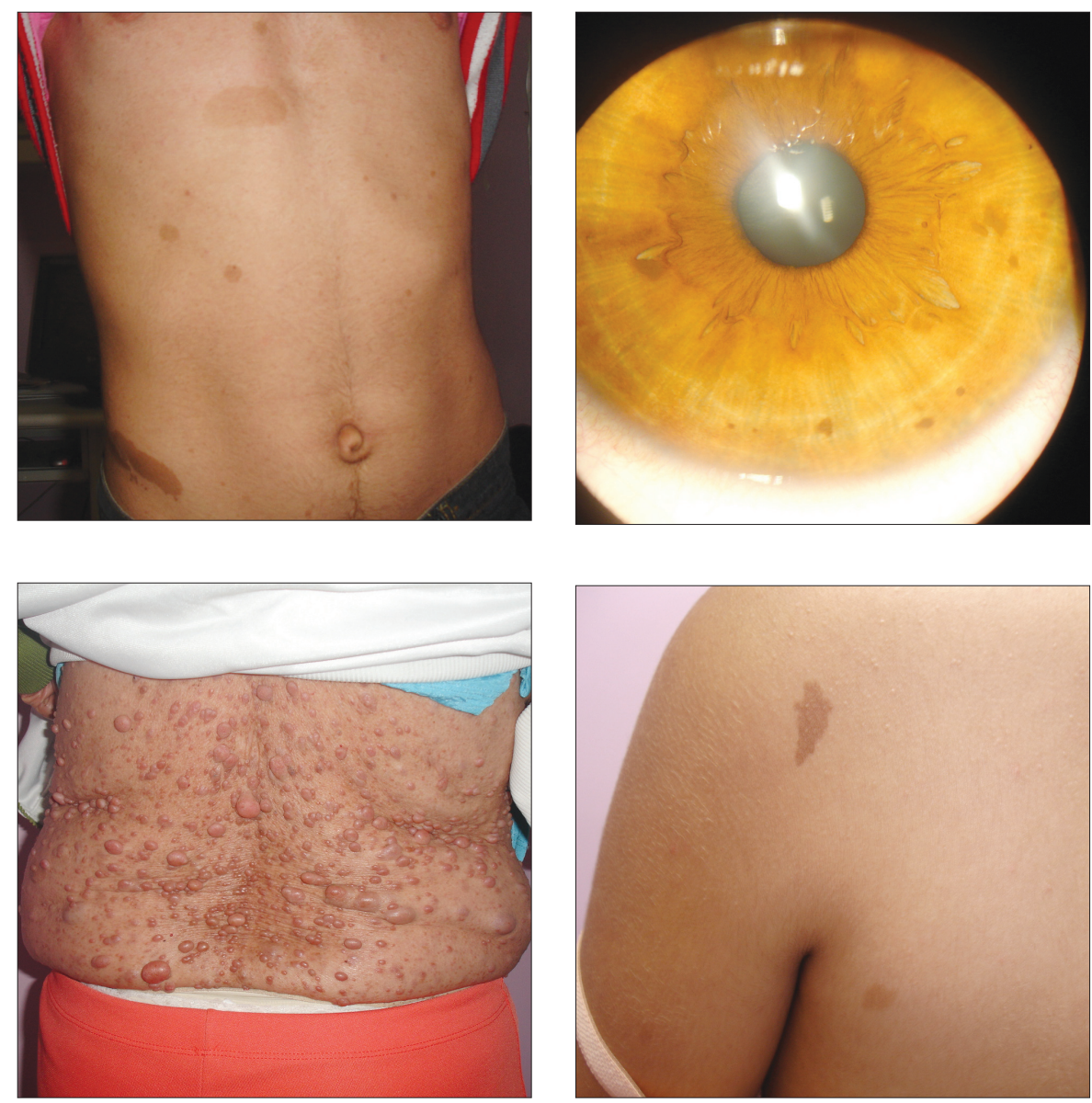

Figure 1: A) Images of the patient showing café-au-lait spots and Lisch nodules

Figure 1: B) Maternal grandmother with neurofibromas and sister with café-au-lait spots 

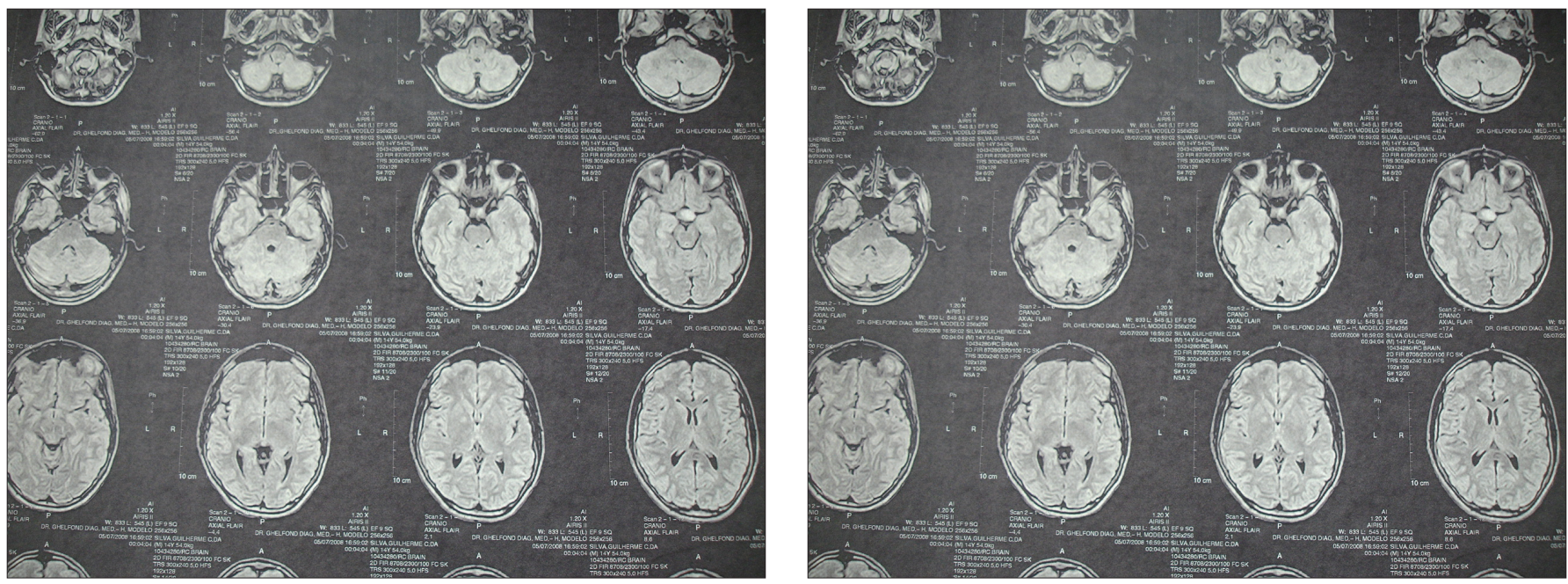

Figure 2. MRI of the brain on T2 and FLAIR sequences showing an optic chiasm mass compatible with glioma

chiasm and hypothalamus, with hyperintense signal on T2weighted images and flair measuring $1.4 \times 1.4 \mathrm{~cm}$ in its greatest paramagnetic contrasts, without mass effect on adjacent structures. (Figure 2)

The patient continues to undergo follow-up in both the ophthalmology and the neurology services, performing serial perimetries and MRIs to monitor the tumour.

\section{Discussion}

Neurofibromatosis type I is a genetic disease characterised by progressive systemic involvement; it presents with physical and neurological changes and ocular findings. ${ }^{(3.4)}$

It is an autosomal dominant disease, and the NF1 gene can suffer mutations which lead to a variety of clinical presentations among affected patients. ${ }^{(1.2)}$

The diagnosis of neurofibromatosis type 1 should be done as early as possible through clinical examination and family history. ${ }^{(4)}$ In our case, the patient has a strong family history with a maternal grandmother and mother diagnosed with NF1 and a sister under investigation for the disease.

Refractive errors can be associated with the condition, with frequent cases of anisometropia, astigmatism and amblyopia. To prevent amblyopia and for early correction of refractive changes, patients should be properly screened before the age of 3 years. ${ }^{(5)}$ In our case, the patient had a visual acuity of 20/32 in both eyes, with low hyperopia in the right eye and slight astigmatism in both eyes.

The most frequent ocular manifestations of the disease include Lisch nodules, hypertelorism, motor disorders, disorders of the optic nerve, and glioma. Of these, Lisch nodules are the most frequent, corresponding to approximately $75 \%$ of ocular manifestations and predominantly located in the lower iris. ${ }^{(2.6)}$ Our patient had Lisch nodules in both eyes, slight temporal pallor of the optic nerve and changes on MRI consistent with glioma.

Optic glioma, although benign, can present aggressively in children. Tumour growth is variable and unpredictable, especially in younger patients. ${ }^{(7)}$ Clinical, neurological and ophthalmic follow-up with serial imaging is recommended to monitor tumour growth. Visual evoked potential can be used as a non-invasive screening method for early detection of glioma in patients with
NF1 and normal visual acuity. ${ }^{(8.9)}$

In paediatric patients with NF1 and optic glioma, visual loss depends on tumour size and location, which can be observed on MRI. Visual loss is more common when post-chiasmatic structures are involved. ${ }^{(10)}$

Typically, only cases of symptomatic optic gliomas whose expansion is seen on imaging studies require treatment. Both chemotherapy and radiotherapy can stabilise tumour growth and even reduce its size. For younger patients, chemotherapy is the first line of treatment, as it shows better effects on tumour growth than radiotherapy. ${ }^{(8.11)}$ Resection is an alternative for tumours involving the optic nerve, but it is only used in patients with loss of visual function or severe proptosis causing pain or exposure keratopathy. ${ }^{(8.12)}$

Spontaneous tumour regression can occur; it is seen as a decrease in tumour size on MRI and a remission of symptoms. The possibility of regression should be discussed when deciding the treatment plan. ${ }^{(13)}$

Tumour location determines the prognosis. Optic nerve gliomas have fewer complications and a lower mortality compared to tumours in the optic chiasm, especially those involving postchiasmatic structures. ${ }^{(10)}$

In our case, the MRI showed an optic chiasm tumour. The patient also had a loss of sensitivity in the temporal hemifields compatible with the location of the tumour. Serial MRIs and perimetries did not show progression of the lesion. Thus, the patient has been undergoing clinical follow-up with serial studies for close monitoring of the tumour and symptoms.

Due to the tumour's potential to affect visual function severely, regular long-term ophthalmic follow-up is recommended. ${ }^{(14)}$ The approach toward patients with glioma should be decided case by case and is based on tumour location and clinical and imaging progression. The risks and benefits of treatment should be weighted. ${ }^{(8)}$

Children with NF1 should be examined as early as possible, preferably before puberty. Early diagnosis through clinical examination, family history and imaging studies is essential for therapeutic monitoring and control of the tumour. NF1 management should aim to anticipate major complications and provide early treatment. In genetic counselling, it is important to inform parents and relatives about the general features of the disease and its complications, emphasising that most patients lead healthy and productive lives. ${ }^{(1.15)}$ 


\section{References}

1. Kordic R, Sabol Z, Cerovski B, Katusic D, Jukic T. Eye disorders in neurofibromatosis (NF1). CollAntropol. 2005;29 Suppl 1:29-31.

2. Ceuterick SD, Van Den Ende JJ, Smets RM. Clinical and genetic significance of unilateral Lisch nodules. Bull Soc BelgeOphtalmol. 2005;(295):49-53.

3. Hwang JM, Cheon JE, Wang KC. Visual prognosis of optic glioma. ChildsNerv Syst. 2008;24(6):693-8.

4. Zeid JL, Charrow J, Sandu M, Goldman S, ListernickR. Orbital optic nerve gliomas in children with neurofibromatosis type 1. J AAPOS. 2006;10(6):534-9.

5. McKeever K, Shepherd CW, Crawford H, Morrison PJ.An epidemiological, clinical and genetic survey of neurofibromatosis type 1 in children under sixteen years of age. Ulster Med J.2008;77(3):160-3.

6. Parsa CF, Hoyt CS, Lesser RL, Westein JM, Strother CM, MuciMendonza R, et al. Spontaneous regression of optic gliomas: thirteen cases documented by serial neuroimaging. Arch Ophthalmol. 2001;119(4):516-29.

7. Darrigo JuniorLG, Bonalumi Filho A, D'AlessandroDSM, GellerM. Neurofibromatose tipo 1 na infância: revisão dos aspectos clínicos. Rev Paul Pediatr. 2008;26(2):176-82.

8. Chang BC, Mirabella G, Yagev R, Banh M, Mezer E, Parkin PC, et al. Screening and diagnosis of optic pathway gliomas in children with neurofibromatosis type 1 by using sweep visual evoked potentials. Invest Ophthalmol Vis Sci. 2007;48(6):2895-902.
9. Akinci A, Acaroglu G, Guven A, Degerliyurt A. Refractive errors in neurofibromatosis type 1 and type 2. Br J Ophthalmol. 2007;91(6):746-8.

10. Liu GT. Optic gliomas of the anterior visual pathway.CurrOpinOphthalmol. 2006;17(5):427-31.Review.

11. Muniz MP, Ferraz FilhoJRL, SouzaAS, ZanussoSH, BertelliECP, Bertollo EMG. Neurofibromatose tipo 1: aspectos clínicos e radiológicos. Rev Imagem. 2006;28(2):87-96

12. Kaufman LM, Doroftei O. Optic glioma warranting treatment in children. Eye(Lond). 2006;20(10):1149-64.

13. Balcer LJ, Liu GT, Heller G, Bilaniuk L, Volpe NJ, Galetta SL, et al. Visual loss in children with neurofibromatosis type 1 and optic pathway gliomas: relation to tumor location by magnetic resonance imaging. Am J Ophthalmol. 2001;131(4):442-5.

14. Nichols JC, Amato JE, Chung SM. Characteristics of Lisch nodules in patients with neurofibromatosis type 1. J PediatrOphthalmol Strabismus. 2003;40(5):293-6.

15. Savar A, Cestari DM. Neurofibromatosis type I: genetics and clinical manifestations. SeminOphthalmol. 2008;23(1):45-51.Review.

\section{Corresponding author:}

Flávia Souza Moraes,

Rua Rui Barbosa, 451, apto 72,

Santo André (SP), Brazil CEP: 09190370 